\title{
Otomycosis in Bikaner: A Clinico-Mycological Study
}

\author{
Geeta Tinna, Sanju Pannuâf $f^{*}$, Anjali Gupta and B.P. Sharma \\ Dept. of Microbiology, SPMC Bikaner, Rajasthan, India \\ *Corresponding author
}

\section{A B S T R A C T}

Keywords

Otomycosis, Fungus, External auditory meatus.

Article Info

Accepted:

28 August 2017

Available Online:

10 September 2017
Otomycosis is often an infection of the pinna, the external auditory meatus, however, the disease may occur in the middle ear if the tympanic membrane is perforated. It is mainly characterized by pruritus, otalgia, aural fullness, hearing impairment and tinnitus. We collected ear swabs or skin scrapings from 150 suspected cases of otomycosis and subjected them for $\mathrm{KOH}$ mount and fungus culture. Out of total 64 cases $(42.6 \%)$ turned out to be caused by fungus only and $39(26 \%)$ cases showed presence of fungus along with bacteria, while $47(31.3 \%$ ) cases did not show presence of any fungus as only pyogenic bacteria were isolated from them. Aspergillus niger (56), Aspergillus fumigatus (22), Aspergillus flavus (10), Aspergillus nidulans (04), Aspergillus terreus (02), Candida albicans (10), Alternaria sp. (02) and Rhizopus (06), Mucor (02) and Penicillium (03) were predominant etiological agents. Ear picking was a predisposing factor in $78(75.7 \%)$ cases followed by use of antibiotic 39(37.8\%), oiling07 (6.7\%). Only 6 cases were

\section{Introduction}

Otomycosis is a fairly common condition encountered in E.N.T. outdoor and in general practice. It is worldwide in distribution and most of fungi causing it are saprophytes, present in soil, mouldy cereal grains, compost etc., which are believed to be possible source of infection. The disease is known to occur in all parts of the world. Highest incidence has been reported from Suez Canal zone'.

Otomycosis known under various synonyms as mycotic otitis externa, Singapore ear, hot weather ear, tropical ear, fungal infection of ear, clinically it is chronic or subacute infection of external auditory canal.

From the ear canal a number of fungi and bacteria can be isolated. It is neither an uncommon nor a serious disease but it causes a great loss in men power working capacity ${ }^{2}$.

There are much controversy among otologists about fungi isolated from infected ear in a tropical climate, in regard to their role as a primary infectious agents or as secondary invaders or as harmless contaminants of a short easily accessible blind $\mathrm{sac}^{3}$.

However fungal infection may become clinically significant in immune compromised patients or patients undergoing long term antibiotics therapy ${ }^{4}$. The incidence of otomycosis is increasing due to unrestricted or unwarranted use of topical antibiotics and corticosteroids. Out being a tropical country, so that the problem of mycotic otitis externa 
(otomycosis) justified a systematized study ${ }^{5,6}$. Fungal infection of ear are quite common here, although Rajasthan is relatively arid zone in this country.

The main aim and objectives of this study to detect the magnitude of the problem of otomycosis in this arid zone and to find out in what particular season this infection is most common and what are the various factors behind it. Morphological identification of fungus in otomycosis by microscopy and culture technique. Also to isolate or find out common species of fungus causing otomycosis. And study of correlation between otomycosis and different predisposing factors: social status, age, sex, symptoms, occupation and seasonal variation, if any.

\section{Materials and Methods}

The prospective study was conducted at mycological laboratory of Department of Microbiology, Sardar Patel Medical College, Bikaner. Total 150 cases were collected from ENT outdoor in P.B.M. Hospital and associated group of hospitals during the month of July 2016 to February 2017 (7 months) to detect mycological profile of otomycosis.

\section{Inclusion Criteria}

Cases with symptoms of external ear disease, who were found to be positive for fungus by direct examination as well as by culture test, were included in the study.

\section{Data collection}

A detailed history was taken regarding the name, age, sex, social status, occupation, predisposing factors, previous history of similar disease, treatment taken in past, particularly systemic or local antibiotic and steroid was also taken. It was also determined if they were having diabetes.

\section{Microbiological methods}

All patient samples were collected under aseptic condition and analyzed at Microbiology lab, SPMC Bikaner The sample were processed for the identification of organisms by the direct microscopy of $10 \%$ $\mathrm{KOH}$ wet mount, Indian ink preparation and Gram's staining and isolates were inoculated on four tubes of SDA (Two tubes of SDA with chloramphenicol and cycloheximide and two tubes without cycloheximide or plane SDA). One tube from each set was kept at $25^{\circ} \mathrm{c}$ and $37^{\circ} \mathrm{c}$ respectively.

Tubes were examined twice a week for presence of growth and discarded at 4 weeks if no growth was seen.

The cultures were considered significant if the same isolate was obtained in more than one tube, the final identification was done after lactophenol cotton blue tease mount, cello phane tape preparation and biochemical tests (slide culture, Germ tube test, sugar fermentation \& carbohydrate assimilation test etc.)

\section{Results and Discussion}

Present study was conducted from July 2016 to February 2017. Maximum number of positive cases $64(62.2 \%)$ were obtained during July to October while least no. of cases $13(12.6 \%)$ were positive in month of November to February.

Out of 150 suspected cases 64 (42.6\%) turned out to be caused by fungus only and 39 (26\%) cases showed presence of fungus along with bacteria, while 47 (31.3\%) cases did not show presence of any fungus as only pyogenic bacteria were isolated from them. Therefore only 103 cases $(64+39)$ showed presence of fungus and were included as positive cases of otomycosis (Table 1). Maximum cases were in age group 16-30yr i.e. 46 (44.5\%) followed by $4-15 y r$ and $31-45 y r$ i.e. $24(23.3 \%)$ and 
$19(18.4 \%)$ respectively. Outdoor activity is maximum in young age which decreases with age.

Males were more commonly affected $61.1 \%$ rather than females $38.9 \%$ showing male predominance. Out of 150 cases highest number were Labourer/farm workers 40 followed by housewives 20 and students 17 . However least number of cases were teachers and office workers i.e. 6 and 8 respectively.
Infection was more prevalent in workers rather than service class people.

$66.9 \%$ of the cases with otomycosis belonged to poorer class of society, $29.3 \%$ belonged to lower middle class and only $3.8 \%$ belonged to upper middle class. Most common predisposing factor was ear picking $(75.7 \%)$ followed by use of antibiotic (37.8\%) (Table 2).

Table.1 Etiological agents

\begin{tabular}{|c|c|c|c|}
\hline \multirow{2}{*}{ S. No } & Etiological agent & \multicolumn{2}{|c|}{ No. of cases } \\
\cline { 3 - 4 } & & No. & \% \\
\hline 1. & Only fungus & 64 & $42.6 \%$ \\
\hline 2. & Fungi + Bacteria & 39 & $26 \%$ \\
\hline 3. & Bacteria & 47 & $31.3 \%$ \\
\hline
\end{tabular}

Table.2 Predisposing factors

\begin{tabular}{|l|l|c|l|}
\hline S. No. & Predisposing factors & No. of cases & Percent \\
\hline 1. & Ear picking & 78 & $75.7 \%$ \\
\hline 2. & Oiling & 7 & $6.7 \%$ \\
\hline 3. & Swimming & 6 & $5.3 \%$ \\
\hline 4. & Use of local and systemic antibiotic & 39 & $37.8 \%$ \\
\hline 5. & Diabetes & 6 & $5.3 \%$ \\
\hline 6. & None & 11 & $10.5 \%$ \\
\hline
\end{tabular}

Table.3 Etiological agents

\begin{tabular}{|l|l|l|l|}
\hline S. No. & Isolated fungi & Number & Percent \\
\hline 1. & Aspergillus niger & 56 & $47.9 \%$ \\
\hline 2. & Aspergillus fumigatus & 22 & $18.8 \%$ \\
\hline 3. & Aspergillus flavus & 10 & $8.6 \%$ \\
\hline 4. & Aspergillus nidulans & 4 & $3.4 \%$ \\
\hline 5. & Aspergillus terreus & 2 & $1.7 \%$ \\
\hline 6. & Candida albicans & 10 & $8.6 \%$ \\
\hline 7. & Alternaria & 2 & $1.7 \%$ \\
\hline 8. & Rhizopus & 6 & $5.1 \%$ \\
\hline 9. & Mucor & 2 & $1.7 \%$ \\
\hline 10. & Penicillium & 3 & $2.6 \%$ \\
\hline & Total & 117 & $100 \%$ \\
\hline
\end{tabular}

Species of fungus isolated from 103 cases 
Table.4 Details of pyogenic organisms isolated

\begin{tabular}{|l|l|l|l|}
\hline S. No. & Pyogenic organisms & Number & Percent \\
\hline & Pseudomonas & 46 & $53.4 \%$ \\
\hline 1. & Coagulase-positive Staph. & 11 & $12.7 \%$ \\
\hline 2. & Citrobacter & 10 & $11.6 \%$ \\
\hline 3. & Proteus & 7 & $8.1 \%$ \\
\hline 4. & Klebsiella & 6 & $6.9 \%$ \\
\hline 5. & E.coli & 6 & $6.9 \%$ \\
\hline & Total & 86 & \\
\hline
\end{tabular}

Commonest complaint was itching/irritation (79.5\%) followed by pain $69.9 \%$ and feeling of fullness $50.4 \%$ of cases. Only 3 cases has complaint of vertigo.

Aspergillus niger was the commonest fungus found and was present in $56(47.9 \%)$ of the infected ears. Aspergillus fumigatus was the second commonest i.e. 22 (18.8\%), Aspergillus flavus associated with 10 (8.6\%). Aspergillus nidulans and Aspergillus terreus were associated with $4(3.4 \%)$ and $2(1.7 \%)$ ears respectively.

Thus Aspergillus species were responsible for the maximum number of otomycosis i.e. 94 $(80.34 \%)$ of the cases.

Candida albicans was isolated from 10 (8.6\%), Alternaria in 2 (1.7\%), Rhizopus in 6 (5.1\%), Mucor in $2(1.7 \%)$ and Penicillium in $3(2.6 \%)$ cases (Table 3 ).

Total 150 cases, pyogenic bacteria were isolated in 86 cases (isolation rate 57.3\%). Out of these 86 bacteria isolates, 39 were associated with fungi and 47 were purely bacterial.

Most predominant of pyogenic organisms isolated were Pseudomonas (53.4\%) species (Table 4).

Otomycosis was first recognized by Mayer (1944) by reporting the presence of fungi in the pus of draining ear. The otomycosis of the external auditory canal is generally considered infrequent and unimportant.

There have been conflicting reports regarding the justification of using the term otomycosis, since some believe that fungi alone are incapable of producing external otitis ${ }^{6,7}$.

Although material was collected from cases of suspected otomycosis only twice or thrice in a week in the ENT outdoor. Out of 150 suspected cases we could find 103 cases, which were positive for fungal elements bt smear as well as culture tests. These were included in this study.

Out of these 103 positive cases, $37.8 \%$ (39 cases) showed presence of fungus with bacteria while $62.2 \%$ (64 cases) yield, due to the fact that most of the cases were on antibiotic treatment, which has subside the bacterial infection and allowed fungus to over grown.

Out of 117 fungal isolates a large majority (80.34\%) were species of Aspergillus namely niger, fumigatus, flavus, nidulans and terreus. All five of them, more so the Aspergillus niger are common aerial contaminants, particularly in the surroundings in which most of the patients lived and worked surprisingly.

Fungal otomycosis is still one of the most important types of external ear infections. In 
the region in which this study was conducted in North-west Bikaner, Aspergillus niger was the predominant fungal aetiological agent. Although candidal otomycosis had a lower rate of incidence, clinicians should be aware of this aetiology especially among 16-30 year olds.

In short it was found that otomycosis, though an age old disease, still presented with challenging aspects of diagnosis and treatment. Isolation of the fungal organism involved is not just an academic exercise but important for clinical cure.

\section{References}

Aneja, K.R., Sharma, C. Joshi, R. Fungal infection of the ear: A common problem in the north eastern part of Haryana, India. International Journal of Pediatric Otorhinolaryngology 2010; 74: 604 607.

Anwarullah, M., and Jayaker, P.A. A
Microbiological study of otomycosis in Visakhapatnum J.Ind. Med. Ass.1987; 85: 229-232.

Falser, N., Fungal infection of the ear. Etiology and therapy with Bifonazole cream or solution. Dermatological 1984; 169(1): 135-140.

Gregson, A.E.W., and Touche, C.J, La. Otomycosis: A neglected disease. J. Laryngology and otology 1961; 75: 4569.

Ismail, H.K., Otomycosis. J. Laryngology and otology 1962; 76: 713-719.

Mayer 1944-quoted by Yassin; Maher A; Moawad, M.K. otomycosis: a survey in the eastern province of Saudi Arabia, J. Laryngology and otology. Oct 1978; 92(10): 869-876.

Saki, N., Rafiei A, Nikakhlagh S, Amirrajab $\mathrm{N}$, Saki S, Prevalence of otomycosis in Khouzestan Province, The Journal of Laryngology \& Otology 2013; 127: 2527.

\section{How to cite this article:}

Geeta Tinna, Sanju Pannuâf, Anjali Gupta and Sharma, B.P. 2017. Otomycosis in Bikaner: A Clinico-Mycological Study. Int.J.Curr.Microbiol.App.Sci. 6(9): 2943-2947. doi: https://doi.org/10.20546/ijcmas.2017.609.361 